\title{
EFFECTS OF MULTIPLE JOB HOLDING ON THE WORK-LIFE BALANCE
}

\author{
Wayne McClintock \\ Nick Taylor \\ Taylor Baines and Associates \\ Julie Warren \\ Centre for Research \\ Evaluation and Social Assessment
}

\begin{abstract}
Multiple job holding is a significant feature of the contemporary New Zealand labour market, with at least one in ten people actively involved in the workforce holding more than one job at a time. Research into the effects of multiple job holding on the lives of workers in three sectors shows there can be considerable impact on their work-life balance. The researchers conducted in-depth interviews with male and female health professionals, farmers, and café or restaurant workers. The research shows that multiple job holding is comparatively well established in the agriculture and health sectors, with multiple job holders expecting to remain as such for the longer term. While multiple job holding may be equally established in the café and restaurant sector, the multiple jobs holders do not generally expect to remain so for long so the multiple job holding appears more transitional. Multiple job holders, who typically work long hours, are motivated by a range of factors, with economic reasons dominating. However, personal factors and putting together a portfolio of work are also important. Overall, workers interviewed in the three sectors tend to hold their jobs because they want to rather than because they have to. Nevertheless, multiple job holding affects lives outside work, particularly family activities, participation in leisure and exercise, and community involvement. These effects on work-life balance vary by sector.
\end{abstract}

\section{Introduction}

Non-standard work has become more prevalent in New Zealand since the restructuring of the economy during the 1980 's. It differs from standard employment in terms of its location, tenure, hours of work, method of remuneration and employee/employer relationships. Nonstandard work can operate through forms such as contracting, temporary work agencies and multiple job holding (De Bruin and Dupuis, 2004: 23).

The increase in non-standard work can be traced, at least in part, to the contingent labour strategy that many companies have adopted. This strategy is based on replacing full-time jobs with contracting arrangements that maintain the same level of activity, but without the security and other benefits associated with standard employment. In many industries, such as agriculture and forestry, a segmented market has emerged to provide labour for the core industry and independent contractors. It includes a primary market for managers, professionals and highly skilled workers, who have relatively secure and well paid jobs, which exists alongside a secondary market for less skilled workers who receive lower wages and have less job security (McClintock and Brown, 2001: 8). Other sectors of the economy where there is a tradition of part-time employment, such as retail, hospitality, and tourism, are also experiencing a growth of non-standard work as employers adapt their practices and schedules to an increasingly competitive environment.
One manifestation of non-standard work is multiple job holding or carrying out paid or unpaid work for more than one employer or family business or farm at a time. It is a significant feature of the contemporary New Zealand labour market. At least one in ten people $(10.1 \%$ in 2001) actively involved in the workforce hold more than one job. This level of multiple job holding provides a reference point for comparing rates across a range of variables including different localities, sectors of the economy and occupational groups (Taylor et al. 2003). For example, the overall rate for rural areas was $20.2 \%$, and even higher among farming occupational groups (e.g. cattle farmer/farm worker at $24.5 \%$ and livestock farmer/farm worker at $21.2 \%$ ). Health professionals also show high rates (e.g. surgeon $39.8 \%$, anaesthetist $38.7 \%$, physician $28.5 \%$ and GP $25.8 \%$ ); while for café and restaurant workers the rates are lower but still above the national average (e.g. waiter $11.8 \%$ and bartender $11.1 \%)$.

Research shows the stress and pressures that people in the workforce have experienced from changes in the way that work is organised and perceived in the interests of more flexibility in the labour market. The concept of work-life balance has grown out of responses to the problems associated with this transition. It refers to strategies that may be applied to help people adjust their work practices (e.g. hours and place of work) to achieve greater flexibility at the work place, and successfully combine these practices with their family and community responsibilities (De Bruin and Dupuis, 2004: 23-24). Work-life balance has recently become a key component 
of research and policy development undertaken by the Department of Labour, Ministry of Social Development and Ministry of Women's Affairs (Callister, 2004: 108). Discovering ways to balance the time demands of paid employment with those due to family and friends is a challenge for individuals and policymakers alike (Callister, 2004: 113).

It seems likely that the effects of multiple job holding that relate to work-life balance, such as maintaining personal and family relationships and involvement in individual and community activities, are more complex than those experienced by people who hold only one job. This paper uses data collected as part of a study of 180 people with multiple jobs to identify those effects. The data focuses on how the particular work practice of multiple job holding affects the personal, family and community dimensions of a person's life, and compares the experiences of people employed in the farming, health and café-restaurant sectors. After describing the research method and the profile of the multiple job holders, the paper discusses their hours of work, other activities that comprise their work-life balance, reasons for and benefits of holding more than one job, and the effects of multiple job holding on their work-life balance.

\section{Research Method and Profile of the Respondents}

The current research programme $e^{\prime}$ aims to provide knowledge about the way individuals, families and communities in New Zealand are adapting to social and economic change through multiple job holding. The programme began in 2001 and is contracted through to 2007. It is anticipated that the research findings will be useful to a range of agencies and groups, including those developing social and economic policy for the labour market, and to urban and rural communities as they respond to social and economic change. The research programme is organised into two main objectives.

Development of a profile of multiple job holding in New Zealand over recent years based initially on 2001 census data for factors such as age, sex, ethnicity, work-force status and occupation, then an analysis of changes 1981 to 2001 and comparisons with other official statistics such as the quarterly Labour Force Survey.

Identification of factors that encourage or inhibit multiple job holding and an assessment of the impacts of multiple job holding on individuals, families and communities through a series of 180 in-depth interviews, with three sectors covered in the first round during 2003-4: farming, health professionals, and café and restaurant workers.

A purposive sample of 60 men and women was selected for each of the three sectors. They were identified through directories, local contacts and snow balling. People were selected to participate in the research if they had more than one job in the course of the most recent week. Those who did not meet this criterion were screened out of the research. The interviews were based on a comprehensive schedule combining closed and open questions and usually took between 60 to 90 minutes to complete ${ }^{2}$.
The profile of the 60 respondents for each of the sectors by sex was farming $43 \%$ male and $57 \%$ female, health $55 \%$ male and $45 \%$ female, and café and restaurants $33 \%$ male and $67 \%$ female. The café and restaurant workers interviewed were much the youngest for the three sectors, with most $(82 \%)$ less than 29 years of age, whereas none of the health or farm sector interviewees were less than 29 years of age. Most of the farmers (73\%) were aged $30-49$ years as were $70 \%$ of the health professionals. The rest of the interviewees in these two sectors were aged 50 years and over. Few of the interviewees were Maori, with only the café-restaurant sector having any interviewees $(8 \%)$ identifying their ethnicity as Maori, or Maori-Pakeha.

The length of time respondents had been multiple job holders varied between the sectors. Many farm workers and health professionals had been committed to this strategy over the long term, while the younger café and restaurant workers were, in general, just starting their working lives and therefore new to any work strategy. In the farming sector, $82 \%$ of those interviewed had held more than one job beyond the previous year; two-fifths had been multiple job holders for 10 years or more. Their average time holding more than one job was 8.5 years. Most $(83 \%)$ health professionals interviewed had also held more than one job beyond the previous year, with $38 \%$ being multiple job holders for at least 10 years. The average time these health professionals had held more than one job was 7.9 years. By contrast, of the 44 (73\%) café and restaurant workers interviewed who held more than one job beyond the previous year, most $(86 \%)$ had been doing so for less than five years. The average time these 44 workers had held multiple jobs was 2.3 years.

\section{Hours Worked by Multiple Job Holders}

If hours of work are an indicator of work-life balance, then multiple job holders may be at more risk of a poor balance. Data from the 2001 census shows on average across the workforce that $46.6 \%$ of the multiple job holders worked 50 or more hours per week compared to $22.4 \%$ for non multiple job holders. The multiple job holders interviewed in the three sectors were also likely to work 50 hours or more per week. Around half of those from both the farm and health sectors, and a third of those from the café and restaurant sector, reported working 50 hours or more in the most recent working week. However, as Callister (2004: 109) points out, a simple indicator of work-life balance, such as 50 hours or more of work per week, may be misleading. He notes that time-use data for New Zealand suggest people in more highly skilled occupations may work longer hours (and earn higher incomes). Yet they usually have a greater degree of control over their schedules and place of work, and usually achieve a better work-life balance than people with less skilled and lower paid occupations (Callister, 2004: 114).

For most multiple job holders interviewed, the total hours worked in the previous week added up to the equivalent of a full time position (or more) although particular jobs in all three sectors are often part time (Table 1). Only a quarter of those in the cafe and restaurant sector and a 
Table 1: Hours Worked by Respondents During the Most Recent Working Week

\begin{tabular}{|l|c|c|c|}
\hline Hours worked in most recent working week & $\begin{array}{c}\text { Farming } \\
\text { per cent }\end{array}$ & $\begin{array}{c}\text { Health } \\
\text { per cent }\end{array}$ & $\begin{array}{c}\text { Café \& Restaurant } \\
\text { per cent }\end{array}$ \\
\hline$<30$ & 20 & 8 & 25 \\
\hline $30-49$ & 32 & 43 & 41 \\
\hline $50-69$ & 42 & 42 & 25 \\
\hline$>70$ & 7 & 7 & 8 \\
\hline & 101 & 100 & 99 \\
\hline
\end{tabular}

Table 2: Other activities on Which Respondents Spent a lot of Time

\begin{tabular}{|l|c|c|c|}
\hline Activities & $\begin{array}{c}\text { Farming } \\
\text { per cent }\end{array}$ & $\begin{array}{c}\text { Health } \\
\text { per cent }\end{array}$ & $\begin{array}{c}\text { Café \& restaurant } \\
\text { per cent }\end{array}$ \\
\hline Studying & 33.3 & 60 & 31.7 \\
\hline Household work & 61.7 & 66.7 & 35 \\
\hline Childcare & 55 & 55 & 11.7 \\
\hline Community/ voluntary work & 50 & 35 & 8.3 \\
\hline Other & 25 & 41.7 & 33.3 \\
\hline Sport & 26.7 & 26.7 & 20 \\
\hline None of these & 3.3 & 5 & 16.7 \\
\hline
\end{tabular}

Note: Sport was not included as a fixed response in this question. It was the most frequent activity reported in the "other" category.

fifth of those in farming said they worked less than a total of thirty hours (the point at which work is defined as full time). In the farming sector all the respondents who worked for less than a total of 30 hours were women.

\section{Other Activities that Comprise the Work-life Balance}

Work-life balance is also affected by the time individuals devote to activities outside the workplace. These activities have personal, family and community functions that contribute to social well-being. We asked respondents whether they usually spent significant time in a range of out of work activities (as shown in Table 2). There were interesting differences across the three sector groups.

- $\quad$ Out of work activities most frequently identified by those in the farming sector included, in descending order, household work, childcare, community/voluntary work, studying and sport. Those in the farming sector were also most likely to identify voluntary work as a "job" they had carried out over the previous year; forty-two (or $70 \%$ ) identified "other jobs" such as voluntary work for schools, churches, community organisations and sports clubs. Thus, the multiple job holders interviewed are making a significant contribution to the social well-being of rural communities.

- The out of work activities that health professionals reported were similar to those of people in the farming sector although fewer identified voluntary/community work and more identified study. In descending order, they identified household work, study, childcare, community/voluntary work, and sport. Given that many of the health people interviewed had academic jobs, the emphasis on study is not surprising.

- The outside activities of the café and restaurant workers interviewed probably reflect their young age. Of the three groups, they were least likely to spend a lot of time on the activities listed. Their most frequently identified activities, but still identified less often that the other groups, were household work and study.

\section{Reasons for Holding More than One Job}

Respondents' reasons for originally adopting this form of employment were varied. Financial reasons (e.g. extra or regular income from assembling a portfolio of jobs to make up full-time hours or more) predominated among people from the farming and café and restaurant sectors. However, there were also a significant number of individuals from these sectors who did so because they wanted to follow a particular profession or occupation; enjoyed a specific lifestyle; or needed social contact with other people. Those from the farming sector who said they had another job for lifestyle reasons either wanted to broaden their interests by having a non-farming occupation or had purchased a farm so they could enjoy a rural lifestyle. By contrast, professional development, interest and satisfaction were of more importance among health professionals than financial reasons such as extra income. It was not uncommon for people from all three sectors who mentioned non-economic reasons to also acknowledge the importance of financial factors.

Respondents also identified a wide range of reasons for remaining as multiple job holders. Although economic factors were often prominent, personal and family circumstances, career ambitions and desire for social 
contact beyond the home and family also influenced their work choices. For two-thirds of both farming and health sector respondents, holding two or more jobs was a matter of choice. For most of the rest $(27 \%)$ their motivation was a mixture of choice and necessity. Conversely, for café and restaurant workers, multiple job holding was more a necessity than a choice. A fifth considered multiple job holding a necessity while a further two-fifths considered it both a necessity and choice.

In their further comments about motivations for having more than one job, the three groups described different motivations. The major motivators for farmers were the pursuit of a career, the enjoyment of an additional job, and economic considerations such as generating funds for debt repayment and capital expenditure, financial independence and an improved standard of living. For health professionals the motivators were the complementary nature of particular jobs in terms of skills and interests, professional enjoyment and stimulation, economic necessity, lifestyle preferences, and an institutional requirement to undertake clinical work with teaching and/or research and vice versa. Café and restaurant workers, however, were mainly motivated by economic considerations, such as extra income and saving for overseas travel, and enjoyment of the variety and the flexibility of holding two or more jobs.

Individuals' decisions about work were also influenced by changes in personal and family circumstances. Events related to the family life cycle, such as starting a family. beginning a long-term relationship/getting married, children's education and planning for retirement, influenced the decision-making of people from the farming and health sectors. Other significant changes described were moving residence, home ownership/mortgage, other family finances and tertiary study. For café and restaurant workers, rather than family circumstances, the most influential changes in personal circumstances related to their youthfulness: tertiary study, moving residence and leaving school.

Women, in particular, described in some detail how their personal and family circumstances affected their worklife balance. Farming women spoke of returning to their previous occupations, changing from part-time to fulltime work or quitting jobs in their attempts to juggle careers with family commitments. Likewise, several women from the health sector described how their current jobs provided flexibility to organise their work schedules around children's needs.

\section{Benefits of Holding More than One Job}

To a large extent the benefits respondents identified from multiple job holding reflected their motivations for such work arrangements. Thus, they described cconomic and social benefits that compensate for the extra effort required to maintain their work-life balance. Most people interviewed regarded variation and stimulation; level of income; social contact and making friends; building work experience; security of income; and keeping their "hand in" as being positive features of their work strategies.
The hours of work provided through multiple job holding was valued by one in two of farming and café and restaurant workers, while two out of five in the farming sector also appreciated its suitability for the family. Farming respondents also valued social contact, personal growth and stimulation, a sense of satisfaction and selfworth and a balanced lifestyle. A small proportion of café workers valued the opportunity to broaden their experience. For some people these benefits were the result of a deliberate choice to have more than one job while, for others, they were an unexpected outcome. Health workers identified the flexibility of work hours, the stimulation and interest of more than one job, the opportunity for professional development, and the "synergy" and "complementarity" of jobs that involve clinical work and academic teaching or research.

Women from the farming and health sectors were more likely than men to report that building work experience, keeping their "hand in", hours of work and suiting their family as benefits of holding more than one job.

Because off-farm employment has become an important source of income for farm families experiencing cyclical commodity prices, rises in farm input costs and climatic events such as drought and floods, people from the farming sector were also asked how their other jobs contributed to the farm business or household. That contribution is complex, but more than anything else the income from these additional jobs was used to maintain the household's lifestyle or to pay for extras to enhance that lifestyle. By comparison, the contribution of that income to farm finances and as preparation for retirement was relatively minor.

\section{Effects on Work-life Balance}

Maintaining a work-life balance for multiple job holders is a delicate juggling act governed by personal and family considerations and the demands of at least two jobs. The impacts on their relationships and out-of-work activities of these jobs may offset many of the benefits described above. Interviewees from all sectors were asked whether holding more than one job helped, hindered or had no effect on a range of relationships and out-of-work activities. There were some general trends. For instance, a number described how achieving an appropriate balance between their work and personal/family lives was an ongoing issue (e.g. "[I] can't do everything"). For some people this balance was easier to maintain in certain circumstances rather than others (e.g. winter months are easier than summer). Several, who were concerned about their relationship with partners, spoke of the need for mutual support, negotiation about childcare, communication and tact, while others admitted they were unable to spend as much time with their children as they would like. All those who commented about their friendships agreed that although established connections were difficult to sustain when they took another job, it was easier to acquire and maintain friendships with workmates and professional colleagues. There were some differences in experience among the three sector groups. 
Those from the farm sector considered that multiple job holding helped their personal relationships and friendships, and involvement in ongoing education, but hindered their care or support of other family members; amount of housework; health/fitness or training; involvement in organised sport, entertainment or leisure; involvement in community activities; and balance between work and personal/family life. They spoke of positive features such as enjoyment, diversity, stimulation, freedom of choice and flexibility, and negative features like tiredness, rural isolation, increased stress levels and little opportunity for time off. These quotes provide some insights:

"[It's] the hours that kill you really" - a spray contractor $\&$ farmer working 70 hours per week.

"The lifestyle is more of a life sentence than a lifestyle" an art teacher \& farmer working 62 hours per week.

"I don't think I'm a boring person to live with or be with. but perhaps I'm too busy for family and friends sometimes. I miss them" - a primary teacher, farmer \& company director working 65 hours per week.

For café and restaurant workers multiple job holding most hindered the balance between work and personal/family life, personal relationships, health and fitness, and entertainment and leisure. Most considered that holding more than one job had no effect on their family relationships and one in two stated that it had no effect on the amount of housework they do. They also described problems organising their jobs around other parts of their lives, for instance the conflicting obligations between jobs. Unusual hours of work and the need to hold at least two jobs to earn a full-time equivalent income are also seen to limit social activities. However, several people noted that these negative outcomes are mitigated to some degree by the financial benefits.

Health professionals believed that multiple job holding most hindered the balance between work and personal/family life, health/fitness or training, and entertainment or leisure. It also hindered the amount of housework they do, family relationships, involvement in community activities and personal relationships. However, they did believe it helped their involvement in ongoing education. Other issues raised included the extra administration from having more than one job, the additional demands on intellect and skills, and the duplication of work demands or stresses. Sometimes these work-related pressures affect the health of individuals, and organisational skills are considered necessary for them to cope with more than one job as well as managing other aspects of their lives.

\section{Conclusion}

The research suggests that achieving a work-life balance is more complex than simply reducing working hours. Most of the people interviewed for this research worked more than 50 hours per week. However, benefits such as income, stimulation, social contact, variety, flexibility and access to study level were often seen as benefits that mitigated the downside of multiple job holding. Most people interviewed, on reflection, concluded that they held more than one job because they wanted to, albeit often in combination with imperatives that took away some choice in the matter.

People spend a lot of time on activities outside work that affect work-life balance. These activities have personal, family and community functions that promote social well-being. Both workers from the farming sector and health professionals devote a lot of that time to household work and childcare. Those from the farming sector in particular devote significant time to voluntary activities, thereby contributing to the social capital of rural communities. Study is a major activity for the health professionals in the sample, many of whom combined academic and teaching jobs with clinical work. A number of young people interviewed in the cafe and restaurant sector were attracted to the flexible work schedules, which allowed them to combine study with paid employment.

There seems to be a link between people's motivations for having more than one job at a time and their commitment to multiple job holding as a lasting work strategy. While economic considerations are often prominent, they are not always the main motivation for multiple job holding. Other considerations such as personal and family circumstances, career ambitions and desire for social contact beyond the home and family also influence people's decisions to hold more than one job. This is especially the case for people interviewed from the farming and health sectors. Those who identified these other motivations seem more likely to want to maintain such working arrangements into the foreseeable future. Conversely, perhaps because the café and restaurant workers were mainly motivated by economic considerations, they are more likely to see multiple job holding as a short term strategy.

Changes in personal and family circumstances play an important part in people's decisions to hold their current mix of jobs. Various stages of the family life cycle clearly shape the decision making of women from the farming and health sectors. While family circumstances were less significant for younger café and restaurant workers, their decisions were influenced by changes in personal circumstances related to their youthfulness: tertiary study, moving residence and leaving school.

The research suggests that multiple job holders receive considerable economic and social benefits from having two or more jobs. These benefits are often seen to compensate for the extra effort required to maintain work-life balance. Most participants in this study identified variation and stimulation, level of income, social contact and making friends, building work experience, security of income, and keeping their "hand in" as positive features of their chosen work strategy. For those from the farming sector, the extra income provided them with the means to maintain or enhance their household's lifestyle. These benefits from multiple job holding need to be investigated further over more sectors. 
Maintaining a suitable work-life balance for multiple job holders is a process of continuous adjustment between the demands of personal and family life and the schedules of at least two jobs. The economic and social benefits derived from this delicate juggling act may be offset to some extent by effects from their jobs on their relationships and activities outside the workplaces that are either hindered or helped by such an employment strategy. These effects on personal, family and community activities are complex as shown by the different impacts across the three sectors. How each individual copes with this juggling act depends on the interaction between a wide variety of personal, social and economic factors. These factors require further careful investigation through quantitative and qualitative research over a number of sectors before government agencies, employers, trade unions and other interested parties can be confident of delivering policy that will enable multiple job holders to maintain a suitable work-life balance.

\section{Notes}

1. The research is funded by the Foundation for Research, Science and Technology, contract TBAX0204.

2. These interviews were conducted by Nicola Robertson, Luke Procter, Julie Warren, Margie
Scotts, Nick Taylor, Cilla Taylor and Wayne McClintock.

\section{References}

Callister, P. (2004). Time-use data and work-life policy development. Social Policy Journal of New Zealand, 22: 108-118.

de Bruin, A. and Dupuis, A. (2004). Work-life balance?: Insights from non-standard work. New Zealand Journal of Employment Relations, 29(1): 21-37.

McClintock, W. and Brown, C. (2001). The nature of work in natural resource dependent industries. Working Paper 30 prepared for the Foundation for Research, Science and Technology Project Resource Community Formation \& Change (TBA X0001). Taylor Baines \& Associates, Christchurch.

Taylor, N., McCrostie Little, H., Baines, J. and Newell, J. (2003). Multiple job holding of farmers in New Zealand. Paper presented at the Agrifoods X conference, Akaroa, 21-24 April. 